\title{
Uluslararası Katılımlı - 4. Ulusal Sağlık Hizmetleri Meslek Yüksekokulları Sempozyumu Raporu
}

\author{
Report of $4^{\text {th }}$ National Symposium of Vocational Schools of Health Related Services with \\ International Participation
}

Naziye ÖZKAN, Hülya GÜÇLÜ, Meral YÜKSEL

$\ddot{O} z$

Bu raporda, 4.Ulusal Sağlık Hizmetleri Meslek Yüksekokulları Sempozyumu'nun içeriğine değinilmiştir. Dokuz yıl aradan sonra İstanbul'da Marmara Üniversitesi Sağlik Hizmetleri Meslek Yüksekokulu tarafindan düzenlenen sempozyum, Sağlık Hizmetleri Meslek Yüksekokullarının sorunları, çözüm önerileri, istihdam sorunları, hasta ve çalışan güvenliği, müfredat çalışmaları, klinik beceri eğitimlerindeki gelişmeler üzerine odaklanmıştır. Farklı konularda sunulan konferanslar dışında çok sayıda poster ve sözlü bildiriler sempozyum programında yer almıştır.

Anahtar Kelimeler: Sağlık Hizmetleri Meslek Yüksekokulu, sempozyum
Meral Yüksel (四)

Marmara Üniversitesi

Sağllk Hizmetleri Meslek Yüksekokulu Tibbi Hizmetler ve Teknikler Bölümü D-100 Güney Yanyolu Üzeri No: 41 / 34758 Kartal İstanbul

e-posta:meralyuksel@marmara.edu.tr

\begin{abstract}
This report refers to the content of the $4^{\text {th }}$ National Symposium of Vocational Schools of Health Related Services. The symposium was organized by Marmara University, Vocational School of Health Related Services in Istanbul after nine years. The symposium was focused on educational problems in Vocational Schools of Health Related Services, solution proposals, employment problems, patient and employee safety, curriculum studies, and developments in clinical skills training. Apart from presenting on different topics, numerous posters and oral presentations were included in the symposium program.
\end{abstract}

Keywords: Vocational School of Health Related Services, symposium

\section{Rapor}

Marmara Üniversitesi Sağlık Hizmetleri Meslek Yüksekokulu ev sahipliğinde düzenlenen "Uluslararası Katılımlı 4. Ulusal Sağlık Hizmetleri Meslek Yüksekokulları Sempozyumu" 15-18 Kasim 2017 tarihleri arasında İstanbul'da 13 konferans, 7 panel, 24 sözlü bildiri ve 18 poster sunumu ile gerçekleştirilmiştir.

İlki 2006 yılında Gazi Üniversitesi, ikincisi 2007 yılında Dokuz Eylül Üniversitesi, üçüncüsü 2008 yılında Van Yüzüncü Y1l Üniversitesi tarafindan düzenlenen sempozyumlar dokuz yil sonra tekrar hayat bulmuştur. $\mathrm{Bu}$ yıl - ilk kez - uluslararası katılımlı gerçekleştirilen sempozyumun bilim kuruluna, eğitim alanında yetkin bilim insanları dahil edilerek, sempozyumun "uluslararasılaşması" konusunda ilk adım atılmıştır.

İstanbul'da özel bir otelin kongre merkezinde düzenlenen toplantının açılış konuşmaları Sempozyum Başkanı Doç. Dr. Meral Yüksel ile İstanbul İl Sağlık Müdürlügü, İl 
Sağlık Müdür Yardımcısı Dr. Muhammed Atak tarafindan yapılmıştır.

Sempozyumun ilk oturumu, Medipol Üniversitesi Sağlık Hizmetleri Meslek Yüksekokulu (SHMYO) Müdürü Prof. Dr. Hanefi Özbek başkanlığında, Trakya Üniversitesi'nden Prof. Dr. Levent Öztürk'ün "Müzik Tedavi Eder Mi?" başlığında sunulmuştur. Öztürk, konuşmasında tamamlayıcı ve alternatif tıp uygulamaları arasında yer alan müzik terapinin tarihimizdeki yeri ve öneminden bahsetmiş, Edirne ve Anadolu'da bulunan şifahanelerdeki uygulama örneklerini sunmuştur. Geleneksel Türk müziğinin en az 1000 yıllık bir geçmişinin olduğundan bahseden Öztürk, çeşitli makamların psikolojik ve iyileştirici etkilerini bilimsel verilere dayanarak açıklamıştır. Oturum sonrası, Marmara Üniversitesi Güzel Sanatlar Fakültesi Orkestrası'nın on yedi öğrencisi Şef Öğr. Gör. Andres Rodrigo Lopez önderliğinde bir konser sunmuştur.

İkinci gün, oturumlar iki ayrı salonda sürmüştür. İlk panel "Öğretim Elemanı Yetiştirilmesi” başlığı altında gerçekleşirken, ikinci panel "Sağlık Yüksekokullarında Alan Dışı Dersler” başlığı altında tamamlanmıştır.

"Öğretim Elemanı Yetiştirilmesi” başlıklı panelin ilk konuşmasını yapan Bezmialem Üniversitesi Tıp Fakültesi Dekanı Prof. Dr. Dilek Sema Arıcı, 'Nasıl iyi öğrenebiliriz, öğretebiliriz?" konulu sunumunda, öğrenme şekillerinden biri olan kolb siklusunun, genelleme, uygulama, deneyim ve yansıtma olmak üzere dört basamaktan oluştuğunu ifade etmiş, sadece öğrenenin değil eğiticinin de öğrenme eylemindeki rolünü vurgulamıştır. Aynı panelde Marmara Üniversitesinden Prof. Dr. Nusret Erdoğan, "Lisansüstü ve Doktora Çalışmaları" başlıklı sunumunda mezun durumundaki sağlık teknikerlerinin lisans ve lisansüstü eğitimleri için çözüm önerileri sunmuştur. Acıbadem Mehmet Ali Aydınlar Üniversitesinden Öğr. Gör. Gülsün Ekicioğlu, “Öğretmeyi Öğretmek” konulu konuşmasında, tekniker olarak mezun olan öğrencilerin beceri yönünden daha donanımlı olmaları gerektiğini söylemiş, bu nedenle laboratuvar eğitiminin önemi ve nasıl olması gerektiği üzerinde durmuştur. "Patoloji Laboratuvar Teknikleri Programı Mezunları için Akademik Kariyer Olanakları" başlıklı konuşmasında Marmara Üniversitesinden Yrd. Doç. Dr. Naziye Özkan, geçilmesi gereken kariyer basamaklarını ve yaşanılan sorunları, aşılması gereken süreçleri açıklamıştır. İstanbul Aydın Üniversitesinden Öğr. Gör. Yeşim Ateş “Meslek Yüksekokullarında Eğitim Veren Öğretim Elemanlarının İstihdam Sorunu" başlıklı çalışmasında, SHMYO' larda istihdam olan akademisyenlerin büyük çoğunluğunun kendi alanlarının dışında üst öğrenime sahip olduklarını tesbit etmiş, verilerini bizlerle paylaşmıştır. Bezmialem Üniversitesinden Yrd. Doç. Dr. İlyas Samet Ergün "Ustalıktan Uzmanlığa" başlıklı konuşmasında, SHMYO eğiticilerinin sadece bilgi ile donatılmış değil, aynı zamanda ustalıklı el becerilerine sahip olmaları gerektiğini bildirmiştir.

“Sağlık Yüksekokullarında Alan Dışı Dersler" panelinde konuşmalarını yapan Marmara Üniversitesinden Doç. Dr. Ayliz Velioğlu Öğünç, Yeni Yüzyıl Üniversitesinden Yrd. Doç.Dr. Süheyla Yazıcıoğlu ve Okan Üniversitesi SHMYO Müdürü Yrd. Doç. Dr. Onur Yarar, SHMYO’ larda verilen Ekoloji, Sağlıkta Toplam Kalite Yönetimi, Fotoğrafçılık, Tıp Fotoğrafçılığı, Tıp Ressamlığı, Sağlık Kültürü, Sağlıkta Tiyatro gibi çeşitli kültür derslerinin öğrencileri sadece teknik beceri veren bir kurumda değil, bir kültür, bir düşünce tabanı oluşturan üniversitede eğitim aldıkları fikrine yakınlaştırdıklarını ifade etmişlerdir. Öğrencilerin "Topluma Hizmet Uygulamaları" gibi derslerle topluma yararlı bireyler olma yolunda adım atacakları bildirilmiştir.

İkinci günün ilk konferansı Hasan Kalyoncu Üniversitesinden Prof. Dr. Zerrin Pelin tarafindan “Gecenin Sirlarına Ortak Olanlar” başlığı ile sunulmuştur. Uyku ve uyku bozuklarının tanı ve tedavisi için temel oluşturan polisomnografi çekimlerini gerçekleştiren uyku teknisyenlerinin yaşadığı ve yaşayabileceği sorunlar konusunda bilgi vermiştir. Pelin, gece terörü, uyurgezerlik, REM uykusu davranış bozukluğu gibi gündüze yansıması hiç olmayan, gece gerçekleşen, uyku hastalıkları sırasında uyku teknisyenlerinin yaşadığ açıklamıştır. Büyük özveri gerektiren bu mesleğin zorluklarına dikkat çeken Pelin, videolu örneklemler ile ilgi çekici bir sunum gerçekleştirmiştir.

İkinci konferans Hacettepe Üniversitesi SHMYO Müdürü Prof. Dr. Fatma Gül Şener tarafından "YÖK Kalite Güvence Sürecinde Hacettepe Üniversitesi Sağlık Hizmetleri Meslek Yüksekokulu" konusunda yapılmıştır. Kurumların kalite güvence sistemi kapsamında, kalite güvence politikalarının oluşturulması, stratejilerin geliştirilmesi ve süreç iyileştirme metodolojileri içeriği ile gerçekleşen sunum, Hacettepe Üniversitesi, SHMYO'nun dış değerlendirme süreci deneyiminin aktarılması ile tamamlanmıştır.

Üçüncü konferansta ise Hacettepe Üniversitesi'nden Doç. Dr. Sanem Şahlı, "Sağlık Hizmetleri Meslek Yüksekokulları ve Uluslararasılaşması” konusunda sunum yapmıştır. Bologna sürecine dahil olan Yükseköğretim kurumlarında, kurumlar arası kalite farklarının azalması, firsat eşitliğinin geliştirilmesi, yeterlilikler ve kalite 
güvencesiyle oluşturulan programlar kapsamında eğitimin yurtdışında tanınması ve hareketliliğin teşviki bakımından öğrenciler yönünden önemi vurgulanmıştır. Öte yandan öğretim elemanlarının da yurt dışında aktif öğrenci grupları ile ders yapabilmesi ve uluslararası bilimsel araştırma yapma firsatı sağladığı bildirilmiştir.

“Önlisans Sağlık Meslekleri Eğitiminde 21. Yüzyıl Becerileri Eğitiminin Kullanılmasının Stratejik Önemi” başlığında Kocaeli Üniversitesi SHMYO Müdürü Yrd. Doç. Dr. Rüştü Taştan, 21. Yüzyıl tıp eğitiminde sağlık ön lisans eğitiminin sosyoekonomik bir katkı sağladığını, nitelikli insan gücünün eğitildiği SHMYO' ların işlevselliğini arttırmak için eleştirel düşünme, iletişim, işbirliği, girişimcilik, esneklik, bilgiye erişim, meraklanma ve hayal kurma unsurlarının beceri eğitiminde önemini anlatmıştır.

“SHMYO'lardaStajSorunlarıveÇözümÖnerileri” paneli İstanbul İl Sağlık Müdürlüğü, İl Sağlık Müdür Yardımcısı Dr. Muhammed Atak, İstanbul İl Sağlık Müdürlüğü Sağlığın Geliştirilmesi Şube Müdürü Özlem Bek Yağmur ve İstanbul İ Sağlık Müdürlüğü Eğitim birim Sorumlusu Mukaddes Miral'ın katılımları ile gerçekleşmiştir. Staj mevzuatı konusunda yürürlükte olan hukuki maddelerin açıklanması ve uygulama süreçleri konusunda bilgi verildikten sonra hastanelere öğrenci yerleştirme sistemi açıklanmıştır. Mevzuat açısından bakıldığında 3308 sayılı Mesleki Eğitim Kanunu, 6331 sayılı İş Sağlığı ve Güvenliği Kanunu ile 5510 sayılı Sosyal Sigorta Kanununa göre uygulamaların sürdüğü vurgulanmıştır. Stajyer kontenjanları, staj ödemelerinin yapılması, öğrencilere sağlık muayenesinin yapılması gibi farklı konularda bilgi alışverişinde bulunulmuş, staj süreçleri değerlendirilmiştir. Panel yoğun katılım ile büyük yankı uyandırmıştır.

"Tıbbi Görüntüleme Teknikleri Eğitiminin Dünü, Bugünü, Geleceği ve Meslek Örgütlerinin Rolü” başlıklı panelin ilk konuşmacısı "Ülkemizde Tıbbi Görüntüleme Teknikleri Eğitiminin Dünü, Öğretim Elemanı Yapılanması Deneyimi” ile Prof. Dr. Nevzat Gürman tarafından sunulmuştur. Marmara Üniversitesi'nden Yard. Doç. Dr. Nuran Akyurt, "Tıbbi Görüntüleme Teknikerlerinin Eğitimi - Türkiye ve Dünya Örneği” başlıklı konuşmasında Tıbbi Görüntüleme Eğitiminin geçmişini, değişimlerini, uluslararası düzeydeki yerini ve gelişme süreçlerini içeren bir sunum yapmıştır. Acıbadem Mehmet Ali Aydınlar Üniversitesi SHMYO Müdürü Prof. Dr. Olcay Çizmeli, "Tıbbi Görüntüleme Teknikerleri Eğitimi - Vakıf Üniversitesi Örneği” başlıklı konuşması ile deneyimlerini aktarmıştır. Sağlık Bilimleri Üniversitesi'nden Yard. Doç.
Dr. Türkan İkizceli, "Yeni Kurulan Bir Üniversite Olan Sağlık Bilimleri Üniversitesi-Sorunları ve Çözüm Önerileri” konulu konuşmasında genç bir üniversite olarak yaşadıkları zorlukları, çözüm önerilerini ve tecrübelerini paylaşmıştır. Türk Medikal Radyoteknoloji Derneği'nden Barış Çavlı, "YÖK Toplantı Sonucu İçeriği Hakkında Bilgilendirme" başlıklı konuşmasında, Tıbbi Görüntüleme Teknikleri Programlarının geleceğine yönelik yapılan girişimleri ve izlenimleri aktarmıştır.

"Patoloji Laboratuvar Teknikleri, Mezuniyet Sonrası Sorunlar" başlıklı panelde Marmara Üniversitesinden Prof. Dr. Nusret Erdoğan, "Patoloji Laboratuvar Teknikerleri Çalışma Grubu”, Üsküdar Üniversitesi’nden Öğr. Gör. Eda Yetimoğlu "İstihdam Sorunları ve Çözüm Önerileri”, Acıbadem Mehmet Ali Aydınlar Üniversitesi'nden Ece Güneyi "Özel Sektör Deneyimi”, Marmara Üniversitesi'nden Başak Atmaca "Üniversite ve Eğitim Hastanesi Deneyimi”, İl Denekler Müdürlüğünden Abdülkadir Bozan "Dernekler Mevzuatı ile ilgili açıklamalar” konularında konuşmalarını yapmışlardır.

Üçüncü gün "Sağlık Sistemlerinde Hasta ve Çalışan Güvenliği” başlıklı panel ile başlamıştır. Acıbadem Mehmet Ali Aydınlar Üniversitesinden Doç. Dr. Serpil Ustalar Özgen "Hasta Güvenliği”, Marmara Üniversitesi'nden Güliz Bülbül "Sağlık Hizmetleri Sektöründe Risk Algısının Çalışan ve Hasta Güvenliği Üzerine Etkisi”, Marmara Üniversitesi'nden Doç. Dr. Nazan Atalan Özlen "Hasta Güvenliğinde Teknik Olmayan Konular (Sosyal ve Kognitif Beceriler)", Av. Nesrin Özkaya "Hasta ve Çalışan Güvenliği Kavramı Açısından Sağlık Mesleği Profesyonellerinin Yasal Sorumlulukları" konulu konuşmalarını tamamlamışlardır.

Bakü'den Sempozyumumuza katılan Doç. Dr. Ramin Bayramlı "Azerbaycan Sağlık Eğitimi” konusunda aydınlatıcı bir konferans vermiştir. Tarihi gelişim sürecinde Azerbaycan sağlık eğitiminin değişim sürecini sunan Bayramlı, günümüz Azerbaycan sağlık sistemini, Tıp, Eczacılık, Diş Hekimliği eğitimindeki süreçleri aktarmış, nitelikli ebe, hemşire ve tekniker bulunmadığını belirtmiştir. Bu amaçla Azerbaycan'da Sağlık Hizmetleri Meslek Yüksekokulları kurmak istediklerini, nitelikli tekniker yetiştirmeyi hedeflediklerini aktarmıştır.

Marmara Üniversitesi'nden Prof. Dr. Berrak Ç. Yeğen, "Bilimde Cinsiyet Farkı" başlıklı konferansında, bilimsel kariyer başlangıcında kadınlar ile erkeklerin sayısının eşit olduğu halde, yüksek akademik pozisyonlara ulaşıldığında, bu sayının kadınlar lehine azaldığını belirtmiştir. Konuşmasında bilim kadınlarından örnekler sunan Yeğen, 
kadınların akademik yaşamda daha etkin rol alabilmesi için öncelikle ayrımcılığın farkına varılması ve proaktif politikalarla eşitsizliğin giderilmesi gerektiğini bildirmiştir.

“Çalışma Ortamında Mobbing” konulu konuşmasını sunan Başkent Üniversitesi SHMYO Müdür Yardımcısı Yrd. Doç. Dr. Şeyda Ökdem, mobbing tanımını yaptıktan sonra mobbing ile karışan ve iş ortamında karşılaşılan olumsuz davranışları sıralamıştır. İş yaşamında özel kurum çalışanlarının, sağlık çalışanlarının ve akademisyenlerin mobbinge uğradığ1, buna karşı bireysel ve kurumsal düzeyde mücadele edilmesi gerektiğini belirtmiştir.

Marmara Üniversitesi'nden Prof. Dr. Goncagül Haklar, "Sağlık Teknikerinden Beklentiler: Hekim Gözüyle" isimli konuşmasında, laboratuvar teknikerlerinin laboratuvarın omurgasını oluşturduğunu, laboratuvar teknikerlerinin zaman baskısına rağmen, işleri doğru yürüten, analitik düşünebilen, karar verme becerisi gelişmiş kişilerden oluşması gerektiğini belirtmiştir.

Sağlık alanında üretilen bilginin yönetilmesi, doğru ve güncel verilere ulaşılması konusu kapsamında "Sağlık Hizmetlerinde Yayıncılık" başlıklı bir konferans sunan Yard. Doç. Dr. Güssün Güneş, sağlık alanında çok sayıda bilimsel derginin olduğunu ancak "Sağl1k Hizmetleri Meslek Yüksekokullarının” özgün alanlarına uygun bilimsel yayınların kısıtlı olduğunu vurgulamıştır.

Atatürk Üniversitesi SHMYO'dan katılan Prof. Dr. Necati Utlu, "Sağlık Sektörü Meslek Eğitiminde Yirmi Y1lık Deneyimlerim, Tespitlerim ve Önerilerim" başlıklı çalışmasında, SHMYO'lar konusunda deneyimlerini paylaşmış, nitelikli insan gücü yetiştirilmesi konusunda alınması gereken tedbirleri, tecrübelerine dayandırarak aktarmıştır.

Marmara Üniversitesi SHMYO'dan Doç. Dr. Nazan Atalan Özlen, tüm sağlık çalışanlarını ilgilendiren "Kadiyopulmuner Resüstasyonda Güncellemeler" başlıklı konferansında aydınlatıcı ve son yeni uygulamaları paylaşmıştır.

İstanbul Yeni Yüzyll Üniversitesi SHMYO Müdürü Prof. Dr. Ömer Bender'in oturum başkanlığında düzenlenen "Yaşlılık ve Yaşlı Bakımı" konulu panelde, İstanbul Yeni Yüzyıl Üniversitesinden Prof. Dr. Demir Tiryaki’nin “'̇htiyarlamadan Yaşlanma”, Prof. Dr. Ersi Kalfoğlu’nun “Global bir Durum Olarak Yaşlılık", Dr. Filiz Albayrak'ın "Yaşıı Bakımı Konusunda Değerlerimiz” ve Yard. Doç. Dr. Deniz Taşkın'ın "Yaşıı Bakım Programı: Sorunlar, Çözüm Önerileri”" başlıkları kapsamındaki renkli sunumları ilgi ile dinlenmiştir.
Sempozyumun son günü Trakya Üniversitesi öğretim üyesi Yard. Doç. Dr. Gülnur Öztürk'ün sosyal ve sağlık alanında güncel bir konu olan "Nefes: İyileşmenin Gücü" başlıklı konferansıyla başlamıştır. Öztürk'ün konuşmasında, nefesin önemi bilimsel veriler 1şığında irdelenmiş, doğru nefes alma teknikleri ile stresle başa çıkmanın ve yaşam kalitesinin arttırılmasının mümkün olduğu vurgulanmıştır. Konferansa katılan dinleyicilere, doğru nefes alma yöntemlerini uygulamalı bir şekilde gösteren Öztürk, sunumu ile büyük ilgi toplamıştır.

Çukurova Üniversitesi, Abdi Sütcü SHMYO Müdürü Prof. Dr. Neslihan Boyan, "Sağlık Hizmetleri Meslek Yüksekokulları'nda Temel Bilimler Eğitiminin Önemi ve Klinik Bilimlerle Entegrasyonu" konulu konferansında, SHMYO eğitim kalitesinin standardize hale getirilmesi için ulusal düzeyde başlatılan Çekirdek Eğitim Programlarının önemine değinmiştir. Müfredat güncelleme çalışmalarında öğrencinin kazanması gereken bilgi, beceri ve yetkinliğin disiplin temelli eğitim yerine disiplinlerin bir araya geldiği entegre (bütünleşik) modellerin kullanılması gerektiğini vurgulamıştır.

Klinik ortamda sağlık öğrencilerini değerlendirmek için kullanılan çok yönlü ve çok amaçlı bir sınav olarak "Objektif Yapılandırılmış Klinik Sınav (OSCE)" başlıklı konu Bezmialem Üniversitesi SHMYO Müdürü Doç. Dr. Gökçen Başaranoğlu tarafından aktarılmıştır. Başaranoğlu, öğrencilere klinik becerileri için üniform test yapılmasına imkan veren tekrarlanabilir, objektif ve kesin bir sinav olması nedeniyle tercih edilmesi gereken OSCE sinavları konusunda deneyimlerini paylaşmıştır.

Celal Bayar Üniversitesi SHMYO Müdürü Prof. Dr. Turan Gündüz "Sağlık Hizmetleri Meslek Yüksekokulları için Yeni Program Önerileri” başlıklı konuşmasında, ülkemizde gelecekte istihdam yönünden ihtiyaç duyulacak teknikerlik programlarını incelemiş, cerrahi robot teknikerliği, medikal tasarım ürün teknikerliği, medikal toksikoloji teknikerliği, engelli bakım ve rehabilitasyon teknikerliği ile diyabet hastalığına yönelik teknikerlik mesleklerinin gereksinim olacağını vurgulamıştır.

Genç bilim insanları, sempozyuma SHMYO'ların çeşitli programlarında yapmış oldukları sözlü ve poster bildirileri ile katılmışlardır. Kapanış töreninde sözlü ve poster bildiri ödülleri sahiplerini bulmuş, dilek ve temenniler dinlenmiştir. 5. Ulusal Sağlık Hizmetleri Meslek Yüksekokulları Sempozyumu'nun Kayseri'de Erciyes Üniversitesi SHMYO tarafından gerçekleştirilmesine karar verilmiştir. 


\section{Teşekkür}

$\mathrm{Bu}$ sempozyum Marmara Üniversitesi Bilimsel Araştırma Projeleri Komisyonu Başkanlığı tarafından SAG-L-081117-0611 numaralı proje ile desteklenmiştir.

\section{KAYNAKLAR:}

1. Uluslararası Katılıml1-4.Ulusal Sağlık Hizmetleri Meslek Yüksekokulları Sempozyumu Özet Kitabı 
